\title{
Obstrüktif Uyku Apne Sendromu (OUAS) Saptanan Hastalarda Vasküler Fonksiyon Bozukluğu ve Ateroskleroz Riskinin Değerlendirilmesi
}

\author{
Elçin Aydın ${ }^{1} \oplus$, Cihan Altın² ${ }^{2}$, Birsen Şahin Satılmış ${ }^{3}{ }^{\circ}$, Erkan Eşki ${ }^{4} \oplus$, \\ Mustafa Agah Tekindal ${ }^{5} \odot$, Muhteşem Ağıldere ${ }^{6} \odot$
}

'Başkent Üniversitesi Tıp Fakültesi, Radyoloji Anabilim Dalı, İzmir, Türkiye ²Başkent Üniversitesi Tıp Fakültesi, Kardiyoloji Anabilim Dalı, İzmir, Türkiye ${ }^{3}$ Başkent Üniversitesi Tıp Fakültesi, Göğüs Hastalıkları Anabilim Dalı, İzmir, Türkiye

${ }^{4}$ Başkent Üniversitesi Tıp Fakültesi, Kulak, Burun, Boğaz Anabilim Dalı, İzmir, Türkiye

${ }^{5}$ Selçuk Üniversitesi, Biyoistatistik Anabilim Dalı, Konya, Türkiye ${ }^{6}$ Başkent Üniversitesi Tıp Fakültesi, Radyoloji Anabilim Dalı, Ankara, Türkiye

Elçin Aydın, Doç. Dr.

Cihan Altın, Doç. Dr.

Birsen Şahin Satılmış, Uzm. Dr.

Erkan Eşki, Doç. Dr.

Mustafa Agah Tekindal, Doç. Dr.

Muhteşem Ağıldere, Prof. Dr.

İletişim:

Doç. Dr. Elçin Aydın

Başkent Üniversitesi Tıp Fakültesi, Radyoloji

Anabilim Dalı, İzir, Türkiye

Tel: +90 5326419164

E-Posta: elcinaydin09@yahoo.com.tr

Gönderilme Tarihi : 280 cak 2018

Revizyon Tarihi : 02 Nisan 2018

Kabul Tarihi : : 17 Nisan 2018

\section{ÖZET}

Amaç: Obstrüktif Uyku Apne Sendromu (OUAS) saptanan hastalarda vasküler endoteliyel işlev bozukluğu ve preaterosklerozis; brakial arter akım aracılı vazodilatasyon (BAAV), karotis arter intima-media kalınlığı (KIMK), mean platelet volume (MPV) ve epikardiyal yağ dokusu (EYD) ölçümü yapılarak değerlendirildi. OUAS hastaları Apne-hipopne indekslerine (AHI) göre gruplara ayrilarak kıyaslandı.

Hastalar ve Yöntem:Hastanemize uyku bozukluğu nedeni ile başvuran ve polisomniografi ile yapılan değerlendirmede AHI değeri 5 ve üstünde bulunan, hiperlipidemi, hipertansiyon, diyabetes mellitus ve bilinen kalp-damar hastalığı olmayan, yaşları 30-70 arası, kadın ve erkeklerden oluşan hastalar çalışmaya dahil edildi. Bu hastalar AHI derecelerine göre hafif-orta ve şiddetli şeklinde gruplandırıldı. Preateroskleroz KIMK, EYD kalınlığı ve MPV ile vasküler fonksiyon ve endotel hücre vazodilatasyonu ise BAEF bakılarak değerlendirildi. İstatistik olarak iki grup arasındaki farklılıklar değerlendirilmek istendiğinde parametrik test ön şartlarını sağladığı durumda "Student's t Test"; sağlamadığında ise "Mann Whitney-U testi" kullanıldı.

Bulgular: 23 hastanın 16 tanesi erkek, 7 tanesi kadındı. Yaş ortalaması 46,30+9,51 (31-65 yaş arası). Hastalar AHI indekslerine göre (hafif:5-15, orta:16-30, şiddetli >30) olarak gruplandırıldığında karşılaştırma için kullanılan parametrelerde anlamlı farklilık saptanmadı.

Sonuç: OUAS hastalarında kardiyovasküler riskin arttığı bilinmektedir. Çalışmamızda bu hastalarda hastalığın şiddeti ile preateroskleroz ve endotel fonksiyonun bozulması arasında bağlantı bulunmamıştır.

Anahtar sözcükler: Obstrüktif uyku apne sendromu, pre-ateroskleroz, endotel fonksiyon bozukluğu

INVESTIGATION OF ENDOTHELIAL DYSFUNCTION AND THE RISK OF ATHEROSCLEROSIS IN PATIENTS WITH OBSTRUCTIVE SLEEP APNEA SYNDROME

\section{ABSTRACT}

Purpose: To investigate endothelial dysfunction and pre-atherosclerosis in patients with Obstructive Sleep Apnea Syndrome (OSAS) by using several parameters including Brachial Artery Flow-Mediated Vasodilation (BAFMV), Carotid Intima-Media Thickness (CIMT), Mean Platelet Volume (MPV) and Epicardial Fat Thickness (EFT). Patients with OSAS were classified according to the Apnea-Hypopnea Index (AHI).

Patients and Methods: OSAS patients who have 5 or more AHI score were enrolled in the study. Patients with hypertension, hyperlipidemia, diabetes mellitus and cardiovascular diseases were excluded. Patients were classified as mild (5-10), moderate $(16-30)$ and severe $(>30)$ according to AHI. These groups were compared to each other in terms of endothelial dysfunction and pre-atherosclerosis markers including BAFMV, CIMT, MPV and EFT. Groups were compared statistically by using either Student's T-Test or Mann Whitney-U test.

Results: Our study population consists of 23 patients with OSAS ( 16 male, 7 female) with the mean age of $46.30 \pm 9.51$ years ranging from 31-65 years. There were no significant differences in all parameters between the mild (5-10), moderate (16-30) and severe ( $>30)$ groups according to AHI.

Conclusion: It is well known that patients with OSAS have an increased cardiovascular risk. In our study, no differences were shown between the progression of the disease and endothelial dysfunction and pre-atherosclerosis markers.

Keywords: Endothelial dysfunction, pre-atherosclerosis, obstructive sleep apnea syndrome 
O bstrüktif Uyku Apne Sendromu (OUAS); 1997'de ASDA (American Sleep Disorders Association) tarafından uykuda tekrarlayan üst solunum yolu tıkanmaları ile karakterize ve sıklıkla oksijen satürasyonunda azalmayla birlikte görülen sendrom olarak tanımlanmıştır. Hastalığın prevalansı \%1-5 bulunmuştur. OUAS'nun kesin tanısı için altın standart olan polisomniografi ile uyku evrelerinin ve çeşitli fizyolojik parametrelerin ayrıntılı olarak incelenmesi gerekir. Uyku Apne Sendromunun kesin tanısı için altın standart polisomniografi ile uyku evrelerinin ve çeşitli fizyolojik parametrelerin ayrıntılı olarak incelenmesi gerekir.

OUAS'da polisomniografi bulguları şunlardır;

- Yüzeyel uykuda (NREM evre 1,2) artma, derin uyku (NREM evre 3,4 ) ve REM periyodunda azalma,

- Sık tekrarlayan apneler ve hipopneler,

- Sık tekrarlayan oksijen desatürasyonu epizodları,

- REM uykusu apnelerin sıklığını, süresini, oksijen satürasyonunun derecesini ve süresini arttırır,

- Apne sırasında paradoksal göğüs ve karın haraketleri görülmesi tipiktir,

- Apne sırasında kalp hızı genellikle yavaşlar ve postapneik dönemde hızlanır, aritmiler görülebilir,

- Solunum sesi kaydında sık tekrarlayan apne epizodları ile kesilen düzensiz, gürültülü horlama duyulur.

Yapılan çalışmalarda OUAS hastalarında kardiyovasküler riskin arttığı belirlenmiş olup nedeninin sempatik aktivite artışı ve vasküler fonksiyon bozukluğu olduğu düşünülmektedir. Uyku sırasında apneik epizodlara bağlı hipoksemi, sistemik hipertansiyon ve artmış sempatik aktivitenin kombine etkisinin ateroskleroz gelişimine yol açtığı saptanmıştır (1-12). Çalışmalarda vasküler hasarlanmayı ve ateroskleroz riskini değerlendirmede brakial arter endotel fonksiyonu, karotis intima-media kalınlığı, epikardiyal yağ yastıkçığı ve mean platelet volume (MPV) değerleri kullanılmaktadır (13-18).

Endotel disfoksiyonu arteriyel endotel duvarındaki yaralanmaya bağlı gelişen bir preaterosklerotik göstergedir. Brakial arter endotel fonksiyonu (BAEF) endotel fonksiyonunu gösteren invaziv olmayan bir yöntemdir (13).

Karotis intima media kalınlığı (KIMK) aterosklerotik damar hastalıklarının subklinik dönemde tanınması ve takibinde kullanılan, kolay ulaşılabilir, basit, ucuz, girişimsel olmayan ve objektif değerlendirme sağlayan bir yöntemdir (14-16). Yapılan klinik çalışmalarda KIMK subklinik aterosklerozun önemli bir göstergesi olduğu bulunmuştur (17).
Epikardiyal yağ dokusu (EYD) koroner arter hastalığı (KAH) gelişimi için bağımsız bir risk faktörü olarak tanımlanmış, ayrıca KAH'da tutulan damar sayısından ve hastanın kliniğinin ciddiyetine kadar birçok konuda değerli bilgiler verebileceği öne sürülmüştür (15).

OUAS'lu hastalarda trombosit aktivasyonunda ve agrevasyonunda artış gösterilmiştir. Mean Platelet Volume (MPV) trombosit hacmi ve aktivasyonunu gösteren bir indikatördür. MPV aynı zamanda aterosklerozu gösteren bir belirleyicidir (18).

Biz bu çalışmada OUAS saptanan hastalarda apne-hipopne indekslerine (AHI) göre yapılan gruplar arasında vasküler endoteliyel işlev bozukluğu ve preaterosklerozis riskini; BAEF, KIMK, MPV ve EYD ölçümü yapılarak karşılaştırdık. OUAS'nda hastalık şiddetine göre endotel fonksiyon bozukluğu ve preateroskleroz gelişimini değerlendirdik. OSAS hastalarında multiparametrik değerlendirmelerde literatürde en kapsamlı parametrelerin çalışmamızda olduğu düşüncesindeyiz.

\section{Yöntem ve gereçler}

Hastanemize Temmuz 2017-Aralık 2017 tarihleri arasında uyku bozukluğu nedeni ile başvuran ve polisomniografi ile yapılan değerlendirmede AHI değeri 5 ve üstünde bulunan, hiperlipidemi, hipertansiyon, diyabetes mellitus ve bilinen kalp-damar hastalığı olmayan, yaşları 30-70 arası, kadın ve erkeklerden oluşan hastalar çalışmaya dahil edildi.

Polisomnografi ile belirlenen AHI değerlerine göre hastalar hafif, orta ve şiddetli olmak üzere gruplandırıldı (AHI: 5-15 = Hafif, 16-30 = Orta, $>30=$ =Ağır).

Hastaların demografik ve antropometrik karakteristikleri kaydedildi. Vücut-kitle indeksi (VKI) hesaplandı, hastalara sigara kullanımı soruldu.

$\mathrm{AHI}$ indekslerini bilmeyen bir kardiyolog tarafından epikardiyal yağ kalınlığı (EYK) ölçümü transtorasik ekokardiyografi (TTE); Vivid S5 e (GE Healthcare, Horten, Norveç) 3S-RS band aralığında; ile sağ ventrikül serbest duvar komşuluğundan, parasternal uzun ve kısa akstan yapıldı. Ölçümler sağ ventrikül duvarına dik olarak, diyastol sonunda gerçekleştirildi. Ölçümlerin tek kardiyolog tarafından yapılması gözlemciler arası uyumsuzluğu minimalize etmektedir (Şekil 1).

Endotel fonksiyonu değerlendirilmesi brakial arter akım aracılı vazodilatasyonun ultrasonografik ölçümü ile 


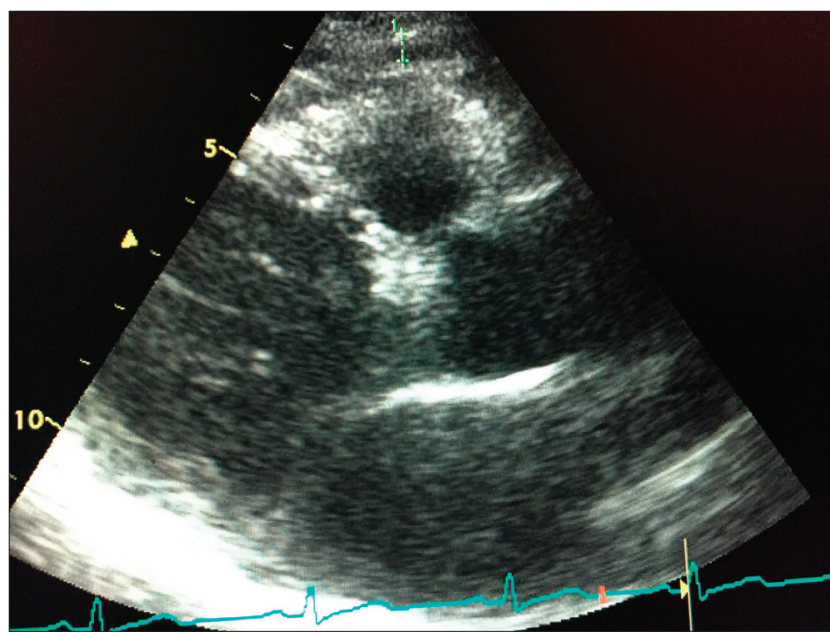

Şekil 1. Transtorasik ekokardiyografi cihazı ile epikardiyal yağ kalınlığı ölçümü

gerçekleştirildi. Hastalar sırtüstü rahat bir pozisyonda yatırılıp ve brakial arter longitudinal düzlemde, antekübital fossanın tam üzerinde palpe edildi. , B-mod ultrasonografi cihazı ile (Arietta-70, Tokyo, Japonya) 9 Mhz prob ile, sağ brakial arter trasesi üzerine konularak, brakial arter, trase boyunca tortüyozitenin olmadığı ve en iyi görüntünün alındığı bölgede longitudinal olarak görüntülendi, lümen ve damar duvarı arasında ön ve arka intimal yüzleri net olarak belirlenebilen bir segment iki boyutlu (2D) görüntüleme için seçildi. Brakial arter çapı (intimadan-intimaya) üç kez ölçüldü ve bu üç ölçümün ortalaması, bazal çap olarak kaydedildi. Brakial arterden alınan bu ölçümler lümen intima arayüzü esas alınarak ön-arka çap olarak ölçülecek ardından ön kola yerleştirilen sfingomanometrik kaf, sistolik kan basıncının ortalama $250 \mathrm{mmHg}$ olacak şekilde şişirilerek 5 dakika süreyle bekletildi. Daha sonra kaf indirilerek brakial arter boyunca reaktif hiperemi oluşturulup arterin longitudinal görüntüsü kaf indirilmeden 30 saniye önce ve 2 dakika sonrasına kadar kaydedildi.

Yapılan ölçümler sonrası endotel kaynaklı dilatasyonu ve endotel fonksiyonunu gösteren

Flow Mediated Dilatation (FMD) aşağıdaki formüle göre hesaplandı (19).

FMD $=$ \%hiperemik akım sonrası ortalama çap - bazal çap/ Bazal çap

Her olgunun karotis intima media kalınlığı, B-mod ultrasonografi cihazı ile (Arietta-70, Tokyo, Japonya) 9 Mhz prob ile, her iki ana karotis arterin yaklașık 1-1,5 cm'lik distal bölümünden, yalnızca posterior duvardan, dörder kez ölçüldü, ölçülen değerlerin ortalaması alınıp kaydedildi (Şekil 2).

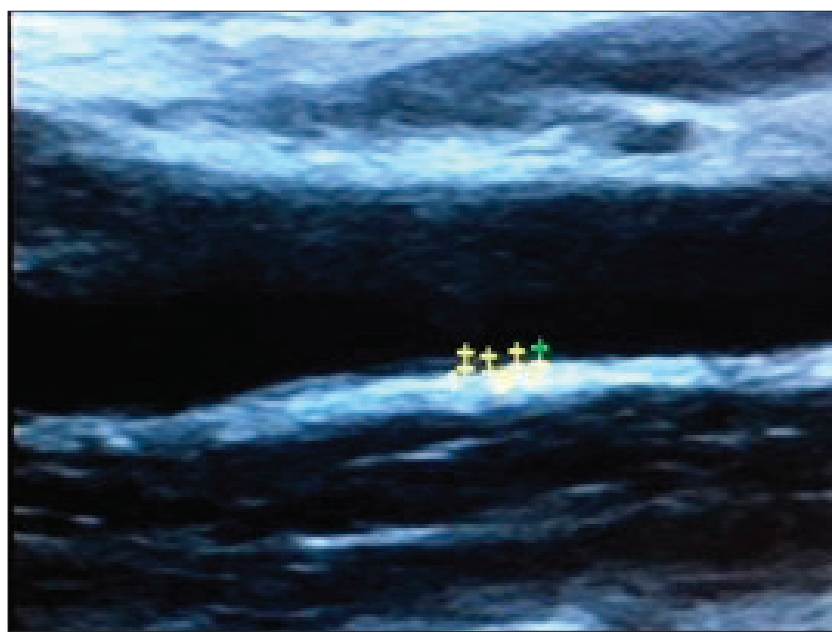

Şekil 2. Ultrasonografi cihazı ile karotis intima-media kalınlık ölçümü

Brakial arter akım aracılı vazodilatasyonu ve karotis intima media kalınlığı AHI indeks değerlerini bilmeyen tek radyolog tarafından ölçüldü.

Hastaların rutin laboratuar tetkiklerinde yapılmış olan hemogram tahlilindeki MPV değeri ateroskleroz açısından diğer bir indikatör olarak değerlendirildi.

Çalışmada önsel güç analizi için, kullanılması öngörülen yöntemlerden biri olan Kruskal Wallis Analizine göre yapılan güç analizleri sonucu, gerekli örneklem genişliği her bir grupta en az 8 denek olarak belirlenmiştir. Bu durumda testin gücü için beklenen değer yaklaşık \%83,38 olarak belirlenmiştir. İstatistik Verilerin değerlendirilmesinde SPPS 20 (IBM Corp. Released 2011. IBM SPSS Statistics for Windows, Version 20.0. Armonk, NY: IBM Corp.) istatistik paket programı kullanılmıştır. Değişkenler ortalama ve Medyan (Maksimum-Minumum) yüzde ve frekans değerleri kullanılmıştır. Ayrıca parametrik testlerin ön şartlarından varyansların homojenliği " Levene " testi ile kontrol edildi. Normallik varsayımına ise "Shapiro-Wilk" testi ile bakıldı. İki grup arasındaki farklılıklar değerlendirilmek istendiğinde parametrik test ön şartlarını sağladığı durumda "Student's t Test"; sağlamadığında ise "Mann Whitney-U testi" kullanıldı. Üç ve daha fazla grup karşılaştırması için Tek Yönlü Varyans Analizi ve çoklu karşılaştırma testlerinden Tukey HSD testi ile sağlanmadığında ise Kruskal Wallis ve çoklu karşılaştırma testlerinden Bonferroni-Dunn testi kullanılmıştır. Kategorik değişkenler arasındaki ilişkiler Fisher's Exact Test ve Ki Kare testi ile analiz edilmiştir. Beklenen frekansların \%20'den küçük olduğu durumlarda bu frekansların analize dahil edilmesi için "Monte Carlo Simulasyon Yöntemi" ile değerlendirme yapılmıştır. İstatistiksel anlamlılık düzeyi $\mathrm{p}<0.05$ olarak kabul edildi. 
Bu çalışmada XXX Üniversitesi'nden etik kurul onayı ve hastalardan yazılı onam belgesi alındı (Proje Numarası: KA17/160).

\section{Bulgular}

23 hastanın 16 tanesi erkek, 7 tanesi kadındı. Yaş ortalaması 46,30+9,51 (31-65 yaş arası) hastalar AHI indekslerine göre (hafif:5-15, orta:16-30, şiddetli >30) olarak gruplandırıldığında en fazla hasta $\mathrm{AHI}$ indeksi şiddetli olan grupta mevcuttu (n:11), AHI indeksi kilo ile doğru orantılı artmaktaydı. Hastaları karşılaştırmak için kullanılan parametrelerde sol atrium çapı (LA) değeri dışında anlamlı farklılık saptanmadı (Tablo 1). EYK ve KIMK değerleri, MPV, endotel fonksiyonu için kullanılan parametreler gruplar arasında anlamlı farklılık göstermemiştir.

Sigara içen ve içmeyen gruplar arasında kilo ve EYK değişkenleri için istatistik olarak anlamlı bir farklıık vardır.
Sigara içen grup daha kilolu olarak bulunmuşken içmeyen grupta EYK daha fazladır (Tablo 2-3).

\section{Tartışma}

OUAS hipertansiyon, koroner arter hastalığı ve diyabetes mellitus için bağımsız bir risk faktörüdür (20). Kardiyovasküler risk faktörü olmasının nedeni hala tam açıklanamamıştır ancak baz hipotezler mevcuttur (21). Bunlardan biri OUAS'lu hastalarda oluşan ve endotel hasarına neden olan oksidatif strestir. Hipoksi sonucu endotel hasarlanır. OUAS'lu hastalarda sempatik sinir sistemindeki fazla aktivasyon damarlardaki aterosklerotik süreci uyarmaktdır. OUAS insülin direnci ve bozulmuş glikoz toleransı ile ilişkli olup sonuçta endotel disfonksiyonunu uyarmaktadır (21). Daha önceki çalışmalarda OUAS hastalarda kontrol grubuna kıyasla nitrat ve nitrit üretimi daha az olduğu kanıtlanmıştır (2224) BAEF endotelden nitrik oksit salınımı sonucunda

Tablo 1. AHI gruplarına göre parametrelerin karşılaştırıması

\begin{tabular}{|c|c|c|c|c|}
\hline & Hafif & Orta & Şiddetli & $p$ \\
\hline Yaş (yıl) & $50,4 \pm 9,94$ & $43,33 \pm 7,06$ & $46,08 \pm 10,47$ & 0,49 \\
\hline Boy (cm) & $170 \pm 1,58$ & $171,17 \pm 12,54$ & $172,67 \pm 7,87$ & 0,83 \\
\hline Kilo (kg) & $80,2 \pm 7,89$ & $99,17 \pm 18,99$ & $100,67 \pm 18,71$ & 0,06 \\
\hline SOL CIMT (mm) & $0,71 \pm 0,05$ & $0,85 \pm 0,14$ & $0,79 \pm 0,18$ & 0,33 \\
\hline SAĞ CIMT (mm) & $0,76 \pm 0,13$ & $0,8 \pm 0,14$ & $0,79 \pm 0,14$ & 0,89 \\
\hline BRAKIAL IMT (mm) & $0,4 \pm 0,07$ & $0,5 \pm 0,09$ & $0,48 \pm 0,11$ & 0,22 \\
\hline BRAKIAL ÇAP (ÖNCESI) (mm) & $3,92 \pm 0,5$ & $4,02 \pm 0,32$ & $4,03 \pm 0,48$ & 0,89 \\
\hline ÇAP KONTRAKSIYON (cm) & $2,74 \pm 0,76$ & $3,5 \pm 0,41$ & $3,17 \pm 0,85$ & 0,27 \\
\hline BRAKIAL DILATASYON (cm) & $4,2 \pm 0,64$ & $4,15 \pm 0,35$ & $4,34 \pm 0,57$ & 0,75 \\
\hline FMD $(\%)$ & $0,07 \pm 0,06$ & $0,03 \pm 0,01$ & $0,08 \pm 0,05$ & 0,12 \\
\hline MPV (fL) & $9,29 \pm 1,91$ & $8,68 \pm 1,73$ & $8,32 \pm 1,37$ & 0,53 \\
\hline LA (cm) & $3,8 \pm 0,19$ & $3,53 \pm 0,57$ & $3,28 \pm 0,4$ & $0,044^{*}$ \\
\hline $\operatorname{LVD}(\mathrm{cm})$ & $4,8 \pm 0,39$ & $4,93 \pm 0,56$ & $4,99 \pm 0,36$ & 0,70 \\
\hline LVS (cm) & $2,96 \pm 0,15$ & $3,27 \pm 0,4$ & $3,25 \pm 0,26$ & 0,16 \\
\hline $\mathrm{RA}(\mathrm{cm})$ & $3,32 \pm 0,29$ & $3,25 \pm 0,36$ & $3,12 \pm 0,22$ & 0,35 \\
\hline $\mathrm{RV}(\mathrm{cm})$ & $2,98 \pm 0,16$ & $2,92 \pm 0,17$ & $2,79 \pm 0,29$ & 0,31 \\
\hline IVS (cm) & $1,2 \pm 0,16$ & $1,13 \pm 0,15$ & $1,21 \pm 0,07$ & 0,42 \\
\hline PW (cm) & $1,16 \pm 0,11$ & $1,1 \pm 0,14$ & $1,15 \pm 0,05$ & 0,51 \\
\hline $\mathrm{EF}(\%)$ & $58,4 \pm 4,39$ & $59 \pm 4,94$ & $59,52 \pm 10,33$ & 0,97 \\
\hline EYK (cm) & $8,82 \pm 1,9$ & $8,17 \pm 1,97$ & $9,46 \pm 2,1$ & 0,45 \\
\hline
\end{tabular}

${ }^{*} p<0,05$

Çalışmaya katılan bireylerin AHI skorlarının kategorileri arasında LA değeri bakımından istatistik olarak anlamlı farkllık vardır.

FMD $=$ \%hiperemik akım sonrası ortalama çap - bazal çap / bazal çap

AHI: Apne-hipopne indeksi, CIMT: Karotis intima media kalınlı̆ı, EF: Ejeksiyon fraksiyonu, EYK: Epicardiyal yağ dokusu kalınlı̆ı, FMD: Flow Mediated Dilatation,

IMT: Intima media kalınlı̆ı, IVS: interventriküler septum kalınlığı, LA: sol atrium çapı, LVD: sol ventrikül diyastol sonu çapı, MPV: mean platelet volum, PW: arka duvar kalınlı̆ı,

RA: sağ atrium çapı, RV: sağ ventrikül çapı. 
Tablo 2. Sigara içen ve içmeyen gruplara göre parametrelerin

karşılaştırıması

\begin{tabular}{|c|c|c|c|}
\hline & Sigara İçmeyen & Sigara İçen & \\
\hline & $n=10$ & $n=13$ & $p$ \\
\hline Yaş & $47,6 \pm 10,99$ & $45,31 \pm 8,53$ & 0,580 \\
\hline Boy & $169,1 \pm 6,71$ & $173,69 \pm 9,04$ & 0,190 \\
\hline Kilo & $83,7 \pm 17,08$ & $105,15 \pm 13,67$ & $0,001^{* *}$ \\
\hline $\mathrm{AHI}$ & $33,72 \pm 21,92$ & $37,26 \pm 26,75$ & 0,740 \\
\hline SOL CIMT & $0,78 \pm 0,14$ & $0,79 \pm 0,17$ & 0,850 \\
\hline SAĞ CIMT & $0,76 \pm 0,1$ & $0,81 \pm 0,16$ & 0,360 \\
\hline BRAKIAL IMT & $0,49 \pm 0,12$ & $0,45 \pm 0,08$ & 0,300 \\
\hline BRAKIAL ÇAP (ÖNCESI) & $3,91 \pm 0,51$ & $4,08 \pm 0,37$ & 0,370 \\
\hline ÇAP KONTRAKSIYON & $3,19 \pm 0,78$ & $3,14 \pm 0,78$ & 0,880 \\
\hline BRAKIAL DILATASYON & $4,17 \pm 0,63$ & $4,33 \pm 0,44$ & 0,480 \\
\hline$\% F M D$ & $0,06 \pm 0,04$ & $0,06 \pm 0,05$ & 0,890 \\
\hline MPV & $8,3 \pm 1,7$ & $8,87 \pm 1,47$ & 0,400 \\
\hline SoA & $3,37 \pm 0,43$ & $3,52 \pm 0,48$ & 0,440 \\
\hline LVD & $4,86 \pm 0,46$ & $4,99 \pm 0,38$ & 0,460 \\
\hline LVS & $3,08 \pm 0,29$ & $3,28 \pm 0,29$ & 0,120 \\
\hline RA & $3,24 \pm 0,31$ & $3,16 \pm 0,26$ & 0,520 \\
\hline RVD & $2,87 \pm 0,2$ & $2,86 \pm 0,28$ & 0,940 \\
\hline IVS & $1,17 \pm 0,16$ & $1,2 \pm 0,06$ & 0,590 \\
\hline PW & $1,11 \pm 0,12$ & $1,16 \pm 0,07$ & 0,200 \\
\hline EF & $58,8 \pm 4,64$ & $59,4 \pm 9,92$ & 0,862 \\
\hline EYK & $10,4 \pm 2,01$ & $7,89 \pm 1,2$ & $0,001^{\star *}$ \\
\hline
\end{tabular}

${ }^{* *} \mathrm{p}<0,01$

Sigara içen ve içmeyen gruplar arasında Kilo ve EYK değişkenleri için istatistik olarak anlamlı bir farklılık vardır.

Tablo 3. AHI grupları ile Sigara içen ve içmeyen grupların karşılaştırıması

\begin{tabular}{|c|c|c|c|c|c|c|c|}
\hline & & & \multicolumn{3}{|c|}{ AHI Skor } & \multirow[b]{2}{*}{ Total } & \multirow[b]{2}{*}{$p$} \\
\hline & & & Hafif & Orta & Şiddetli & & \\
\hline \multirow{4}{*}{$\begin{array}{l}\text { Sigara } \\
\text { Kod }\end{array}$} & \multirow{2}{*}{ İçmeyen } & $\mathrm{n}$ & 3 & 2 & 5 & 10 & \multirow{6}{*}{0,663} \\
\hline & & $\%$ & 30,0 & 20,0 & 50,0 & 100,0 & \\
\hline & \multirow{2}{*}{ İçen } & $n$ & 2 & 4 & 7 & 13 & \\
\hline & & $\%$ & 15,4 & 30,8 & 53,8 & 100,0 & \\
\hline \multirow{2}{*}{\multicolumn{2}{|c|}{ Toplam }} & $n$ & 5 & 6 & 12 & 23 & \\
\hline & & $\%$ & $21,7 \%$ & 26,1 & 52,2 & 100,0 & \\
\hline
\end{tabular}

AHI: Apne-hipopne indeksi oluşan ve endotel fonksiyonunu gösteren bir belirteçtir $(19,22,25,26)$. Yapılan çalışmalarda OUAS'lu hastalarda kardiyovasküler hastalık riskinin arttığı ve BAEF bozulduğu gösterilmiştir (27). 2017 tarihli metaanalizde; yapılan çalışmalarda OUAS şiddeti ile BAEF azalmanın korele olduğu bulunmuştur (27). Biz çalışmamızda OUAS şiddetine göre yapılan grupların birbirleriyle karşılaştırılmasında anlamlı farklılık ayırtetmedik.

EYK kardiyometabolik risk, koroner arter hastalığı, subklinik ateroskleroz, insülin direnci ve metabolik sendromla bağlantııdır. Yapılan çalışmalarda OUAS'lu hastalarda EYK kalınlığında artış tespit edilmiştir ve EYK hastalık şiddeti ile orantılıdır (20). Biz çalışmamızda OUAS'nun şiddeti ile EYK arasında anlamlı fark bulamadık.

OUAS'da kardiyovasküler patolojiye neden olan ve endotel disfonksiyonu, arteriyel kan basıncında yükselme, karotid intima-media kalınlığında artışa yol açan mekanizmalar; apne bağlantılı hipoksi, hiperkapni, sempatik hiperaktivite, oksidatif stres ve sistemik inflamasyondur (21, 29-32) Aterosklerotik riski gösteren KIMK OUAS'lu hastalarda daha yüksek ölçülmekle birlikte hastalığın şiddeti ve KIMK korelasyon göstermektedir (33). Bizim çalışmamızda KIMK ile OUAS şiddeti arasında korelasyon ayırtedilmedi.

MPV trombosit aktivasyon ve agregasyonunu gösteren ve kardiovasküler hastalıklarla yakından ilişkili bir göstergedir. Kanbay ve arkadaşlarının (34), Varol ve arkadaşlarının (35) yaptığı çalışmalarda kontrol grubu ve OUAS şiddetine göre ayrılan gruplar arasında koroner arter hastalığı ve gruplar arası MPV değerleri açısından anlamlı fark bulunmuştur. OUAS'lu hastalarda MPV'nin arttığı ve kardiyovasküler risk açısından anlamlı olduğu sonucuna varılmıştır. Buna karşın Kurt ve Yıldız'ın (36) ve Sökücü ve arkadaşlarının (37) yaptığı çalışmalarda ise OUAS şiddetti ile MPV arasında anlamlı ilişki bulunmamıştır. Bizim çalışmamızda da OUAS şiddeti ile MPV arasında anlamlı ilişki saptanmadı.

Çalışmamızda bu zamana kadar OUAS'nuna yönelik araştırmaların aksine hastalık şiddeti ve KIMK,EYK, BAEF ve MPV arasında korelasyon ayırtedilmemiştir. Bu durumun hasta populasyonumuzdaki azlığa bağlı olduğu düşünülmektedir. Daha geniş populasyonlu ve daha kapsamlı çaıışmalar OUAS'nun hayatımıza etkisini belirlemekte faydalı olacaktır.

Metaanalizlerde kontrol grubuna gore OUAS'lu hastaların preateroskleroz ve endotel fonksiyon risklerinin arttığı gösterilmiştir. Biz çalışmamızda kanıtlanmış olan bu bulgu 
yerine OUAS şiddetinin hastalar üzerine etkisini araştırmayı planladık. Mevcut çalışmalardan daha geniş parametreler kullanarak hastalığın etkilerini şiddeti orantısında gözlemlemeyi amaçladık. Çalışmamızın kardiyovasküler risk

\section{Kaynaklar}

1. Karadağ M, Yavuz Z. Uyku Apne Sendromu. Erişim: http:// uykubozuklugu.uludag.edu.tr/literatur1.htm

2. Köktürk O. Uykuda solunum bozuklukları. Tarihçe, tanımlar, hastalık spektrumu ve boyutu. Tüberküloz Toraks Derg 1998;46:187-92.

3. Carlson JT, Hedner JA, Ejnell H, Peterson LE. High prevelance of hypertension in sleep apnea patients independent of obesity. Am J Respir Crit Care Med 1994;150:72-7. [CrossRef]

4. Linberg E, Janson C, Gislason T, Svärdsudd K, Hetta J, Boman G. Snoring and hypertension: a 10 year follow up. Eur Respir J 1998;11:884-9. [CrossRef]

5. Nieto FJ, Young TB, Lind BK, Shahar E, Samet JM, Redline S, et al. Association of slep-disordered breating, sleep apnea, and hypertension in large community based study. JAMA 2000;283:182936. [CrossRef]

6. Lavie $P$, Herer $P$, Hoffstein V. Obstructive sleep apnea syndrome as a risk factor for hypertension: population study. BMJ 2000;320:47982. [CrossRef]

7. Silverberg DS, Oksenberg A. Essential hypertension and abnormal upper airway resistance during sleep. Sleep 1997;20:794-806. [CrossRef]

8. Andreas S, Schul R, Werger G, Kreuzer H. Prevalence of obstructive sleep apnea in patients with coronary artery disease. Cor Artery Dis 1996;7:541-5.

9. Schafer H, Koahler U, Ploch T, Peter JH. Sleep-related myocardial ischemia and sleep structure in patients with obstructive sleep apnea and coronary heart disease. Chest 1997;111:387-93. [CrossRef]

10. Quan SF, Howard BV, Iber C, Kiley JP, Nieto FJ, O'Connor GT, et al. The Sleep Heart Healty Study: Design, rationale, and methods. Sleep 1997;20:1077-85. [CrossRef]

11. Peker Y, Hedner J, Norum J, Kraiczi H, Carlson J. Increased Incidens of Cardiovascular Disease in Middle-aged Men with Obstructive Sleep apnea: A 7-year Follow-up. Am J Respir Crit Care Med 2002;166:15965. [CrossRef]

12. Mooe T, Rabben T, Wiklund U, Franklin KA, Eriksson P. Sleepdisordered breathing in men with coronary artery disease. Chest 1996;109:659-63. [CrossRef]

13. Chung S, Yoon IY, Shin YK, Lee CH, Kim JW, Lee T, et al. Endothelial Dysfunction and C-Reactive Protein in Relation with the Severity of Obstructive Sleep Apnea Syndrome. Sleep 2007;30:997-1001. [CrossRef]

14. Simon A, Gariepy J, Chironi G, Megnien JL, Levenson J. Intima-media thickness: a new tool for diagnosis and treatment of cardiovascular risk. J Hypertens 2002;20:159-69. [CrossRef]

15. American Diabetes Association. Diagnosis and Classification of Diabetes Mellitus. Diabetes Care 2010;33:S62-9. [CrossRef]

16. Poredos P. Intima-media thickness: indicator of cardiovascular risk and measure of the extent of atherosclerosis. Vasc Med 2004;9:4654. [CrossRef]

17. Lim TK, Lim E, Dwivedi G, Kooner J, Senior R. Normal value of carotid intima-media thickness: a surrogate marker of atherosclerosis: quantitative assessment by B-mode carotid ultrasound. J Am Soc Echocardiogr 2008;21:112-6. [CrossRef] faktörlerinin tanısında kullanılan pek çok parametrenin birlikte kullanılmasıyla OUAS'lu hastaların hastalık şiddetleri ile kardiyovasküler riskin değerlendirilmesinde faydalı olduğu düşünülmüştür.
18. Sarioglu N, Demirpolat G, Erel F, Kose M. Which Is the Ideal Marker for Early Atherosclerosis in Obstructive Sleep Apnea (OSA)- Carotid Intima-Media Thickness or Mean Platelet Volume? Med Sci Monit 2017;23:1674-81. [CrossRef]

19. Coretti MC, Anderson TJ, Benjamin EJ, Celermajer D, Charbonneau F, Creager MA, et al. Guidelines for the ultrasound assessment of endothelial-dependent flow mediated vasodilation of the brachial artery: a report of the international brachial artery reactivity task force. J Am Coll Cardiol 2002;39:257-65. [CrossRef]

20. Kostopoulos K, Alhanatis E, Pampoukas K, Georgiopoulos G, Zourla A, Panoutsopoulos A, et al. CPAP therapy induces favorable shortterm changes in epicardial fat thickness and vascular and metabolic markers in apparently healthy subjects with obstructive sleep apnea-hypopnea syndrome (OSAHS). Sleep Breath 2016;20:483-93. [CrossRef]

21. Ciccone MM, Scicchitano P, Mitacchione G, Zito A, Gesualdo M, Caputo $P$, et al. Is there a correlation between OSAS duration/severity and carotid intima-media thickness? Respir Med 2012;106:740-6. [CrossRef]

22. Del Ben M, Fabiani M, Loffredo L, Polimeni L, Carnevale R, Baratta $F$, et al. Oxidative stress mediated arterial dysfunction in patients with obstructive sleep apnoea and the effect of continuous positive airway pressure treatment. BMC Pulm Med 2012;12:36. [CrossRef]

23. Ohike Y, Kozaki K, lijima K, Kojima T, Ohga E, Santa T, et al. Amelioration of vascular endothelial dysfunction in obstructive sleep apnea syndrome by nasal continuous positive airway pressure-possible involvement of nitric oxide and asymmetric NG, NG-dimethylarginine. Circ J 2005;69:221-6. [CrossRef]

24. Ip MSM, Lam B, Chan LY, Zheng L, Tsang KWT, Fung PCW, Lam WK. Circulating nitric oxide is suppressed in obstructive sleep apnea and is reversed by nasal continuous positive airway pressure. Am J Respir Crit Care Med 2000;162:2166-71. [CrossRef]

25. Joannides R, Haefeli WE, Linder L, Richard V, Bakkali EH, Thuillez C, Lüscher TF. Nitric oxide is responsible for flow-dependent dilatation of human peripheral conduit arteries in vivo. Circulation 1995;91:1314-19. [CrossRef]

26. Cooke JP. Flow, NO and atherogenesis. Proc Natl Acad Sci U S A 2003;100:768-70. [CrossRef]

27. Wang Y, Xu H, Qian Y, Guan J, Yi H, Yin S. Patients with Obstructive Sleep Apnea Display Decreased Flow-Mediated Dilatation: Evidence from a Meta-Analysis. Med Sci Monit 2017;23:1069-82. [CrossRef]

28. Parish JM, Somers VK. Obstructive sleep apnea and cardiovascular disease. Mayo Clin Proc 2004;79:1036-46. [CrossRef]

29. Ryan S, Taylor CT, McNicholas WT. Systemic inflammation: a key factor in the pathogenesis of cardiovascularcomplications in obstructive sleep apnoea syndrome? Thorax 2009;64:631-6. [CrossRef]

30. Olson LJ, Olson EJ, Somers VK. Obstructive sleep apnea and platelet activation: another potential link between sleep disordered breathing and cardiovascular disease. Chest 2004;126:339-41. [CrossRef]

31. Kario K. Obstructive sleep apnea syndrome and hypertension: mechanism of the linkage and 24-h blood pressure control. Hypertens Res 2009;32:537-41. [CrossRef]

32. Suzuki T, Nakano H, Maekawa J, Okamoto Y, Ohnishi Y, Yamauchi M, Kimura $\mathrm{H}$. Obstructive sleep apnea and carotid-artery intima-media thickness. Sleep 2004;27:129-33. [CrossRef] 
33. Kaynak D, Göksan B, Kaynak H, Degirmenci N, Daglioglu S. Is there a link between severity of sleep-disorder breathing and atherosclerotic disease of the carotid arteries? Eur J Neurol 2003;10:487-93. [CrossRef]

34. Kanbay A, Tutar N, Kaya E, Buyukoglan H, Ozdogan N, Oymak FS, et al. Mean platelet volume in patients with obstructive sleep apnea syndrome and its relationship with cardiovascular diseases. Blood Coagul Fibrinolysis 2013;24:532-6. [CrossRef]

35. Varol E, Ozturk O, Gonca T, Has M, Ozaydin M, Erdogan D, Akkaya A. Mean platelet volume is increased in patients with severe obstructive sleep apnea. Scand J Clin Lab Invest 2010;70:497-502. [CrossRef]
36. Kurt OK, Yildiz N. The importance of laboratory parameters in patients with obstructive sleep apnea syndrome. Blood Coagul Fibrinolysis 2013;24:371-4. [CrossRef]

37. Sökücü S N, Özdemir C, Dalar L, Karasulu L, Aydın Ş, S Altın. Is Mean Platelet Volume Really a Severity Marker for Obstructive Sleep Apnea Syndrome without Comorbidities? Pulmonary Med 2014:754839. [CrossRef] 